\section{THE HYGIENE OF ASYLUMS FOR THE INSANE.}

By Richard Greene, F.R.C.P.Ed., etc., Medical Superintendent County Asylum, Northampton.

WHeN the President suggested to me that I should read a paper to the Congress on Asylum Sanitation,* I answered that there was scarcely anything in which the hygiene of asylums differed from that of an ordinary house; that special contrivances for the use of the insane had become rarer and rarer, until at the present day such institutions very much resembled large mansions or hospitals for ordinary cases ; or, more correctly, something between mansions and hospitals. The spacious wards and abundance of light and air remind us of hospitals, while the furniture and home comforts give them more the appearance of mansions. At least, those would be the impressions made on a casual visitor who went round any one of our best provincial asylums. Nevertheless, there are a few points wherein certain differences exist; a few principles which should guide those about to build or fit up institutions for the care and cure of the insane. It is my intention to touch lightly on these points-to steer as widely as possible from mere theories-and to state what has apparently been borne out by an experience of twenty years as an asylum medical officer.

Site.-First, as to site. It has ever seemed to me that the majority of our county asylums are built in situations too high and exposed for our variable English climate. It is not likely that our forefathers experimented much with the thermometer; but they knew that houses built in low places were warmer, so far as the sensations of the inmates were concerned, than those placed on or near the summits of hills. Hence we find that very many of the old manor houses occupy low and sheltered situations. At the present day we have quite forsaken the example of our ancestors in most things, and it is not to be wondered that we have forsaken it in this also. If the asylum were to be used by people in perfect health, nothing need be said against these hill-top sites. They would, for instance, be admirably adapted for barracks or schoolhouses, but for lunatic asylums I am satisfied that the principle has been carried too far, more especially in the asylums for the northern districts of England. These bleak, exposed sites render the buildings much more difficult to warm, and the out-door recreation of the more feeble patients has to be greatly curtailed. I would, therefore, advise that an asylum be built on ground with just sufficient rise to permit of easy and perfect drainage, and the building should be sheltered, from the north and east at all events, by higher ground and by thick belts of trees placed not too near it. The ground to the south should be en-

- Read at the Hastings Sanitary Congress, I889. tirely open, and the building should face almost due south. As it seems undesirable to allow too great a conglomeration of men under one roof, I would limit the size of an asylum to seven hundred or eight hundred beds, or to one thousand at the very outside. The ground on which the building stands, and as much as possible of the surrounding land, should be subjected to deep sub-soil drainage. It has been proved that this deep drainage is. conducive to an hygienic state of any building, the death-rate from phthisis, among other diseases, being notably reduced.

In height, the building should not exceed two stories. The walls should be either hollow, or lath and plastered inside-the latter preferable. By either of these not only may a more equitable temperature be maintained, but damp is prevented from coming through the walls. Some modification of the block principle of construction should be adopted, and day-rooms and dormitories should be so planned that efficient cross ventilation can be readily carried out in them. This is absolutely essential, and yet it is curious to notice how often it has been overlooked.

Water Supply.-The water supply is a matter of primary importance, and it ought to be sufficient to allow thirty gallons a-day to each person resident. If the water be hard, it should be passed through one of the many softening machines now in use for the purpose. To drink water containing much carbonate of lime can hardly be conducive to the general health or welfare of the patients, and it is more than probable that it is a positive cause of disease in some people. The rain-water falling on the roofs of our county asylums is fairly pure, and some simple means of filtration, such as Curzon's filters, would probably render its use perfectly safe.

Warming.-Perhaps the most important part of the hygiene of an asylum is that which pertains to the warming of the wards; and after having devoted much attention to the subject, I am sure that open fire-places, occasionally supplemented by other means, are still the best-in fact, the only wholly satisfactory means. In using the open fireplace we imitate Nature, inasmuch as the rays of heat from the fire resemble the rays from the sun in passing through the air without appreciably warming it. Air can only be warmed by coming in contact with warm bodies. All other methods actually warm the air which we breathe, and to inhale this warm air constantly must have an injurious effect on the animal economy. Of course I speak of air warmed unduly. That slightly warmed air may be breathed without ill effects there can be no doubt, and although I am not able to say what degree of temperature may be safely inhaled habitually, I am confident that it is much lower than is generally supposed. If anyone doubt this let him contrast the cool invigorating sea breeze, bringing health and life on its wings, with the hot air from the desert, 
laden with disease and death. Probably the different amount of ozone in these may account for something, but not for all, nor nearly all. Again, in those countries where rooms are warmed by enclosed stoves or by coils of hot-water pipes, we are likely to find a high relative proportion of lung affections, and a tendency among the people generally to listlessness and inactivity, sure to induce some form of disease unless counteracted by outdoor exercise. In America, for instance, phthisis is commoner than in England, and Mr. Leeds, in a treatise on ventilation, published at New York, declares that this heated air "is the great curse of the American people. It is that dry, lifeless, withering, debilitating, poisonous stuff with which most of our best houses and public buildings, and, most unfortunately, many of our schoolhouses too, are filled and warmed, and which is filling our systems, and warming and drying the life and substance out of about two-thirds of the people of this country."*

Open fireplaces are, however, expensive methods of warming a large building, and entail much trouble if they have to be kept up during the night. It is, therefore, desirable to supplement them by some other method, and no other plan has answered so well in my hands as one of the numerous modifications of the slow combustion stoves. These stoves are cheap-at least, compared with hotwater apparatus-very economical in the consumption of fuel, and undoubtedly effectual. They can be kept up with the slightest attention during the night (in fact, the larger sizes will need no attention at all for 12 or 14 hours), and even in the coldest weather the patients when they leave their dormitories find a fairly well-warmed atmosphere in the dayrooms before the open fires have had time to burn up. I should say here, for the information of those not familiar with asylums, that the vast majority of the patients are out of bed during the day; differing in this respect from the inmates of hospitals.

Corridors of communication, dining-halls, chapels, and all other parts not used much by patients, may be warmed solely by enclosed stoves, as no injury is likely to result during the short time these places are occupied, and of course they need not be warmed beyond a safe point. In single-bedded rooms, occupied by lunatics, open fire-places can rarely be trusted, and it is hardly too much to say that no really good method has yet been invented to effect the purpose. Where the single-bedded room adjoins the nurse's room or corridor the warming can readily be effected by the use of a tubular fire-back in the nurse's room or corridor, or by conveying the warm air from a George's Calorigen, or by a grating in the recess wherein is placed a slow combustion stove. I have

* Stevenson's House Architecture. Vol. II., page 219. tried all these, and find them all efficient. The real difficulty exists where single-bedded rooms are placed in rows. Here we must fall back on steam or hot-water. All or any of these methods are not only justifiable but imperative, inasmuch as. heated air is less injurious to an invalid than a very low temperature, and it is always advisable to choose the least of two evils. This is no departure from the principle I have stated, and I repeat that wherever the open fire can be safely used, it should be used as being at once the most natural, the most cheerful, and as a great help to ventilation.

Ventilation.-Next in importance to warming an asylum, or rather running parallel with it, is the system of ventilation pursued. It is generally easy enough to warm a building by one or more of the means named in the preceding paragraphs, and it is not at all difficult to ventilate it; but when warming and ventilating have to be combined, as they must be for eight or nine months every year in our English climate, we find that the question of admitting pure air involves a problem not always easy of solution. We have all been taught at college, but we are apt to forget it afterwards, that a man exhales one hundred and sixty grains of carbon every hour, upwards of thirty ounces of watery vapour are given off every twenty-four hours, and to retain the latter in vapour two hundred cubic feet of air are needed every hour. When the carbonic acid exceeds I' 5 per thousand volumes, it is very apt to cause unpleasant symptoms, and although very dangerous in itself, it is an index of other impurities, such as organic effluvia. The cubic space allowed in asyiums is six hundred feet in dormitories, and four hundred and eighty in dayroom per patient; but the infirm wards are supposed to have rather more cubic space. If we admit that the maximum impurity permissible is 7 of carbonic acid per thousand volumes, then, as pointed out by Wilson in his book of Hygiene, two thousand cubic feet of fresh air must be supplied every hour to each patient. Three thousand cubic feet would be necessary in the infirm wards, and more would be desirable. We therefore arrive at the fact that it is necessary to renew our six hundred feet of sleeping air at least four or five times every hour. Now, how is this to be done? In American asylums the ventilation by fans worked by steam power is one of the usual plans employed, while in England it is rarely used, being, in fact, unnecessary, as we are fortunately free from the extremes of temperature common in the States. During the summer months the time-honoured custom of opening windows for the renewal of the air answers well enough, and if the windows are constructed, as they always should be in asylums, with a fanlight at top, no draught need be experienced. As it is desirable to move the air on the floor line, there ought to be several gratings in the skirting-board fitted with sliding shutters. During the colder months, open windows and 
gratings are to the majority of patients almost unbearable, and it must be remembered that in many of the insane the nerve force is low, causing changes in the temperature to be easily felt and badly borne. At the same time, if health is to be maintained, our two or three thousand cubic feet of fresh air must be supplied. The Manchester grateback, and the tubular grate-back already referred to, admit a considerable amount of warmed fresh air, but supposing a ward contains sixty patients, and has, in addition to the stoves, four open fire-places fitted with either of these contrivances, it is clear that they will not admit the required hundred and twenty or bundred and eighty thousand cubic feet of air every hour, and making allowance for what passes through the badly fitting doors and windows, they must be supplemented by other means. In some asylums warmed air is drawn into the wards through gratings placed in a juxtaposition to coils of steam of hot-water pipes, and this system is said to answer fairly well. Tobin's tubes form a very ready means of introducing fresh air. They possess the great advantage that they may be easily fitted to any building, and they may be closed at pleasure. For extracting the vitiated air, many inventions have been tried. A system of pipes carried from the various rooms, gathered into a larger pipe in the roof of the building and ending in a flue, at the base of which is a powerful gas jet, answers well, and is really most useful in heavy, moist weather, when the external air seems almost stagnant. Sometimes these pipes join the main chimney flues, or they may be conducted close to the part of the roof in which the hot-water tanks are placed. Flues constructed in the chimneys alongside the smoke flues act fairly well, so long as the adjoining fires are being used. These flues should open close under the ceilings, and down draught may be prevented by an Arnott's valve. Perbaps we lay too much stress on the extraction of vitiated air by special means. If fresh air be freely admitted, there is not much fear but that the foul air will find its way out.

The electric light has already made its appearance in two or three asylums. Its substitution for gas in all of these institutions is only a question of time, and it will be a great help in maintaining purity of atmosphere during the winter months at least.

Drainage.-The drainage of an asylum may conveniently be divided into three stages. Firstwithin the building; second-beyond the building; and third-its disposal. Within the building, by far the most important point for consideration is the arrangement of the closets. These should be in a small block by themselves, merely connected with the ward by a passage. This passage need not be long, indeed, it is better short, as being less likely to act as a flue. Some modification of the Unitas w.c. pan would seem to be the best. I prefer those made of enamelled iron, and the basin and trap should be cast in one piece. The afferent pipe should pass straight from the trap to the soil pipe, never burrowing under the floor as is so commonly found. As the insane often put articles of clothing and brushes down the closets, the trap should be fitted with a brass screw plug about two and a half or three inches in diameter. The soil pipe should invariably be placed outside the building. It should not be less than four and a half or five inches in diameter, and it should run up about four feet beyond the eaves. The lower end should terminate in an inspection pit covered with an air-tight lid to prevent the escape of sewer gas. It is sometimes recommended to have the lid perforated, but this is clearly a mistake, as sewer gas will pass into the open air close to the building, under the level of the windows, and is certain to be drawn inside the asylum. A trap at the distal end of the grating would prevent this, but a trap in the continuity of a drain is very likely to be often obstructed. The main drains should be of glazed sanitary pipes, first of six inches diameter, then of nine inch, and finally of twelve inch. Lately sanitarians have advised drain pipes of a much smaller calibre; the object, of course, being to ensure a complete flushing of the tubes. Brick culverts are not desirable. When well clear of the building, the main drain should be ventilated, and a nine-inch pipe should connect the highest point of the drain with the main chimney. This will ensure the gas in the drain being drawn up; probably decomposed, and certainly dispersed in the air at a height free from all danger. Quite recently Dr. Wiglesworth, of the Rainhill Asylum, has introduced a new system of ventilating drains. The main sewer is connected with the main flue of the furnaces close to the damper, and thus the sewer gas is drawn into a very hot part of the flue, where decomposition doubtless takes place. Dr. Wiglesworth finds that with this system there is a down draught from the usual ventilating pipes, and the gas is taken directly and at once away from the building. The baths and slop sinks must be carefully trapped, and should deliver on to open gullies also trapped. It is a good plan to arrange the baths so that the waste water flows into an, inspection pit of the closet, and thus frequent flushing of the drain from its origin is certain to take place. In spite of every care which can be taken, sewer gas will sometimes penetrate the building; and to aid in the detection of the faulty point, Paine's Drain Rockets may be used. The main drain should be conducted several hundred yards from the asylum and into a depositing tank, where the solids are left, and whence the liquid part flows straight on to the land to be irrigated. It is said that the excretæ of each individual are worth about seven shillings and sixpence per annum, and we await some discovery whereby the chemist can transmute them into gold. 
In the meantime we must be satisfied with some system of disposal which is without danger to the lives of those dwelling near, and if profitable so much the better. One author tells us that sewage passing on to the land evolves a considerable amount of ozone. If this be so, we may one day find that the neighbourhood of sewage farms will become a favourite site for residences. We know that consumptive patients have ere now been advised to breathe the vitiated atmosphere of a cowshed. The air of gas works has been prescribed in some spasmodic diseases, and it would be strange if sewage shouldn't have its virtues praised for one of the many ills of life.

Baths.-It used to be said, perhaps it is still held by some, that the insane exhale a peculiar odour, and that by it alone the disease may be diagnosed. That there is such a thing as the asylum odour is true ; but that it is peculiar to the insane, or at least to any considerable number of them, I have the greatest doubt. At any rate, whatever be the smell, it shows that the skin is not properly discharging its functions, and indicates the necessity for frequent ablutions. Hence the bathing arrangements should be on the most liberal scale. Considering the value of the Russian and Turkish baths as therapeutic agents, it is strange that they should be so little used in our English asylums. It is questionable whether one-fourth of them are fitted up with these adjuncts, which I look upon as absolutely necessary.

Clothing.-As already stated, the nerve-force of the insane is often low, and they are easily affected by changes of temperature. Hence their clothing should be light, yet warm and sufficiently porous to permit of free exhalation from the skin. The underclothing should be of such material as will be a safeguard against chills, and also such as will permit of easy and frequent washing. The same applies to bed-clotbing.

Furniture.-The furniture of an asylum should be strong and comfortable, and the coverings and stuffings of seats ought to be made of some nonabsorbing material. Carpets should not be much used. The floors, if of oak or pitch-pine, may be rubbed with the old-fashioned beeswax and turpentine. If of common wood, they may be laid down in linoleum, or simply stained and varnished. Either of these plans will render the floors impervious, and obviate the necessity for frequent scrubbing and washing. The constant scrubbing of floors, and the evaporation of water consequent thereon, are scarcely in harmony with correct ideas of hygiene. Curtains and hangings should be sparingly employed, but where the windows are made with hopper fanlights, short curtains or valances may be used with advantage, as when the hopper is open the curtain will direct the fresh air towards the ceiling, whence it will fall down in a gentle spray, and no draught will be felt. Whatever wall colouring be used, it should be either susceptible of frequent renewal or be of such material as will not spoil by washing. Varnished paper or the new wall covering known as "Tectorium," fulfils the last-named condition.

Food.-So far, then, we have housed the patient, warmed him, have given him pure air to breathe, and clothed him comfortably; but all these would be unavailing without a sufficient supply of wholesome food. An adult man doing a moderate amount of work-and no lunatic ever does more than very moderate work-needs about four and a half ounces of nitrogenous food, and about thirty ounces of carbonaceous food daily. In all asylums the ordinary diet for patients is regulated by the visiting justices. It is always sufficient, and in some asylums it is above the standard required by authorities or dietetics. The consumption of alcoholic drinks has of late years been greatly reduced in many asylums. In some it has been totally given up as an ordinary article of diet, and in others it is limited to a little table beer, given rather as a reward to those who work than with any idea that it is in any sense a food. Even as an adjunct to the diet of the sick, it is much less used now than formerly. One medical superintendent stated in his annual report for $r 887$, that "the use of alcoholic stimulants in the treatment of diseases, and as an addition to the diet of the feeble and aged, was gradually and almost completely discontinued. In this change there can be no doubt we made a decided advance in rational treatment." The infirmary diet is left to the discretion of the medical officers. There is consequently no danger of error on the side of insufficiency. Cases of acute insanity are, as a rule, feeble and emaciated when admitted-sometimes to an extreme degree-and as convalescence approaches, the diet needed is far in excess of what any scientific diet scale states to be necessary.

Exercise-A paper treating of asylum hygiene would be incomplete without some reference to physical exercise. As I have reached the limit of time allowed for this paper, it will be sufficient to mention that, excepting the more violent of outdoor games, all others are indulged in and are useful in maintaining physical bealth and in promoting mental recovery.

Isolation of Phthisical Persons by the Georgians.-According to Dr. Babaye the Georgians have long held a belief in the contagiousness of consumption, the name for it in their language being "chiekki", the contagious disease. They put the theory into practice. The sufferers are isolated; a nurse carries them food and drink, but they are not allowed to associate with the healthy. 